https://doi.org/10.18800/iusetveritas.201703.017 (c) $\underset{\substack{\mathrm{gy} \\ \mathrm{gy}}}{\mathrm{f}}$

\title{
Extensión de los Convenios Colectivos de Trabajo y Sindicatos Minoritarios ${ }^{(*)}$
}

\section{Extension of the Collective Labour Agreement and Minority Unions}

\author{
Jorge Toyama Miyagusuku ${ }^{(* *)}$ \\ Pontificia Universidad Católica del Perú
}

Alfredo Torres ${ }^{(* * *)}$
Pontificia Universidad Católica del Perú

Resumen: El presente trabajo versa sobre un tema de debate en la actualidad del Derecho Colectivo del Trabajo, el cual es la procedencia de la extensión de convenios colectivos de trabajo de sindicatos minoritarios a favor de trabajadores no sindicalizados. Para empezar, los autores señalan la base constitucional del Derecho Colectivo del Trabajo. Asimismo, indican que existe mucho dualismo entorno a la aceptación de la extensión de los convenios colectivos suscritos por un sindicato minoritario. Llegan a esa conclusión luego de haber revisado unos casos de la jurisprudencia laboral peruana, así como de pronunciamientos administrativos sobre el tema. Finalmente, concluyen que es factible que se extienda el convenio colectivo, siempre y cuando no se vulnere el derecho de libertad sindical.

Palabras Clave: Derecho Laboral - Derecho Colectivo del Trabajo Extensión de Convenios Colectivos - Convenios Colectivos de Trabajo Sindicatos Minoritarios - Libertad Sindical

Abstract: This paper is about a current Collective Labour Law matter
of debate, which is the provenance of the extension of collective labour
agreements of minority unions in favor of the non-unionized workers. To
start, the authors point the constitutional basis of the Collective Labour Law.
Likewise, they refer that exists a strong dualism regarding the acceptance of

$\left.{ }^{*}\right) \quad$ Nota del Editor: este artículo fue recibido el 10 de noviembre y su publicación fue aprobada el 18 de noviembre del 2017.

${ }^{* *}$ Magíster en Derecho Constitucional por la Pontificia Universidad Católica del Perú. Profesor principal de la PUCP. Profesor en la Universidad del Pacífico, la Universidad de Piura y la Academia de la Magistratura. Miembro extraordinario de la Asociación IUS ET VERITAS. Correo electrónico: jtoyama@mafirma.com.pe

${ }^{* * *}$ Bachiller en Derecho de la PUCP. Asistente de Docencia de Maestría en Derecho del Trabajo y Seguridad Social en los cursos de Globalización y Trabajo Decente, y Derechos Laborales y Comercio Internacional dictados en la PUCP. Ex Miembro de la Asociación Civil Derecho \& Sociedad de la PUCP. Correo elctrónico: alfredoj.torres@pucp.pe 


\section{Extensión de los Convenios Colectivos de Trabajo y Sindicatos Minoritarios Extension of the Collective Labour Agreement and Minority Unions}

the extension of the collective agreements signed by a minority union. They arrive to this conclusion after reviewing some of the Peruvian Labour case law, as well as some administrative pronouncements on this field. Finally, they conclude saying that is possible that the collective agreement it be extended, provided that the right of union freedom is not affected.

Keywords: Labour Law - Collective Labour Law - Extension of Collective Agreements - Collective Labour Agreements - Minority Unions - Union Freedom

Sumario: 1. Introducción_2. Derecho Colectivo del Trabajo: contenido constitucionalmente protegido y desarrollo constitucional_2.1. Derecho a la libertad sindical_2.2. Derecho a la negociación colectiva: contenido y eficacia_3. Convenio Colectivo: eficacia personal, general y limitada_4. Jurisprudencia y pronunciamientos administrativos entorno a las extensiones de convenios colectivos_4.1. Tribunal Constitucional: ¿Contradicción de sentencias? 4.2. Corte Suprema: ¿Mantiene una postura definida?_4.3. SUNAFIL: ¿Postura razonable?_5. Propuesta de solución_6. Conclusiones

\section{Introducción}

El presente artículo toca uno de los temas que mayor debate está generando en las relaciones colectivas de trabajo: la procedencia de la extensión de convenios colectivos de trabajo de sindicatos minoritarios a favor de trabajadores no sindicalizados. ¿Es obligatorio, facultativo o está prohibida la extensión de convenios colectivos?

Para responder la interrogante anterior, comenzaremos por un desarrollo constitucional y jurisprudencial del Derecho Colectivo del Trabajo (En adelante, "DCT"), con la finalidad de que a partir de ello centralicemos el debate a un nivel constitucional. Posteriormente, trataremos sobre el sistema de libertad sindical que propone nuestro ordenamiento jurídico (Texto Único Ordenado de la Ley de Relaciones Colectivas de Trabajo [En adelante "LRCT"], aprobado por Decreto Supremo No. 010-2003-TR-y su respectivo Reglamento, contenido en el Decreto Supremo No. 011-92-TR) con especial detenimiento en la temática propuesta. Finalmente, comentaremos los diversos pronunciamientos que nuestro Tribunal Constitucional, la Corte Suprema y la Superintendencia Nacional de Fiscalización Laboral han emitido sobre el tema bajo análisis.
En este sentido, el artículo jurídico tendrá la siguiente estructura: i) Marco general del Derecho Colectivo del Trabajo: contenido y desarrollo constitucional, ii) Convenio colectivo: eficacia personal general y limitada, iii) Jurisprudencia y pronunciamientos administrativos entorno a la extensión de los convenios colectivos y; iv) Nuestra Opinión sobre la extensión de convenios colectivos suscritos por sindicatos minoritarios.

\section{Derecho Colectivo del Trabajo: contenido constitucionalmente protegido y desarrollo constitucional}

Para iniciar nuestro análisis respecto a la materia que abordaremos en el presente artículo, partiremos señalando lo expresado por la Constitución Política del Perú (En adelante "CPP") de 1993 con relación al Derecho Colectivo del Trabajo. Así en el artículo 28 de la Carta Magna se indica que:

"El Estado reconoce los derechos de sindicación, negociación colectiva y huelga. Cautela su ejercicio democrático: 1. Garantiza la libertad sindical. 2. Fomenta la negociación colectiva y promueve otras formas de solución pacífica de los conflictos laborales. La convención colectiva tiene fuerza vinculante en el ámbito de lo concertado. 3. Regula el derecho de huelga para que se ejerza en armonía con el interés social. Señala sus excepciones y limitaciones".

De esta manera, que no quepa duda de que el Derecho Colectivo de Trabajo tiene una vital importancia en la formación de un Estado Democrático, en la medida de que otorga legitimidad a los trabajadores organizados con la finalidad de ser un contrapeso de la facultad de dirección del empresario. 


\section{Jorge Toyama Miyagusuku y}

\section{Alfredo Torres}

Su importancia es vital también porque el DCT (En adelante, "DCT") es parte del cuerpo normativo de Tratados de Derechos Humanos Internacionales ${ }^{(1)}$, entre los cuales se encuentra las siguientes:

- Numeral 4 del artículo 23 de la Declaración Universal de Derechos Humanos, referido a que toda persona tiene derecho a fundar sindicatos y a sindicarse para la defensa de sus intereses.

- Artículo 22 del Pacto Internacional de Derechos Civiles y Políticos, referido a que toda persona tiene derecho a asociarse libremente con otras, incluso el derecho a fundar sindicatos y afiliarse a ellos para la protección de sus intereses; el ejercicio de tal derecho sólo podrá estar sujeto a las restricciones previstas por la ley que sean necesarias en una sociedad democrática, en interés de la seguridad nacional, de la seguridad pública o del orden público, o para proteger la salud o la moral públicas o los derechos y libertades de los demás.

- Artículo 8 del Pacto Internacional de Derechos Económicos, Sociales y Culturales, referido a que los Estados Partes en el presente Pacto se comprometen a garantizar: a) El derecho de toda persona a fundar sindicatos y a afiliarse al de su elección, con sujeción únicamente a los estatutos de la organización correspondiente, para promover y proteger sus intereses económicos y sociales. No podrán imponerse otras restricciones al ejercicio de este derecho que las que prescriba la ley y que sean necesarias en una sociedad democrática en interés de la seguridad nacional o del orden público, o para la protección de los derechos y libertades ajenos.

- Artículo XXII de la Declaración Americana de los Derechos y Deberes del Hombre, que destaca que toda persona tiene el derecho de asociación para promover, ejercer y proteger sus intereses legítimos de orden político, económico, religioso, social, cultural, profesional, sindical o de cualquier otro orden.

- Artículo 16 de la Convención Americana sobre Derechos Humanos, referido a que todas las personas tienen derecho a asociarse libremente con fines ideológicos, religiosos, políticos, económicos, laborales, sociales, culturales, deportivos o de cualquiera otra índole.

- Artículo 8 del Protocolo Adicional en materia de Derechos Económico, Sociales y Culturales, que reconoce el derecho de los trabajadores a organizar sindicatos y a afiliarse al de su elección, para la protección y promoción de sus intereses. Como proyección de este derecho, los Estados partes permitirán a los sindicatos formar federaciones y confederaciones nacionales y asociarse a las ya existentes, así como formar organizaciones sindicales internacionales y asociarse a la de su elección. Los Estados partes también permitirán que los sindicatos, federaciones y confederaciones funcionen libremente.

- Asimismo, se indica que nadie podrá ser obligado a pertenecer a un sindicato. Este último enunciado es muy importante para el reconocimiento del derecho negativo del derecho a la sindicación, dado que es el único documento internacional que consagra este derecho.

(1) Conforme así lo indica la Cuarta Disposición Final y Transitoria que indica lo siguiente: "Interpretación de los derechos fundamentales Las normas relativas a los derechos y a las libertades que la Constitución reconoce se interpretan de conformidad con la Declaración Universal de Derechos Humanos y con los tratados y acuerdos internacionales sobre las mismas materias ratificados por el Perú". Asimismo, relacionado con el artículo V del Código Procesal Constitucional, que menciona lo siguiente: "Interpretación de los Derechos Constitucionales El contenido y alcances de los derechos constitucionales protegidos por los procesos regulados en el presente Código deben interpretarse de conformidad con la Declaración Universal de Derechos Humanos, los tratados sobre derechos humanos, así como de las decisiones adoptadas por los tribunales internacionales sobre derechos humanos constituidos según tratados de los que el Perú es parte". 


\section{Extensión de los Convenios Colectivos de Trabajo y Sindicatos Minoritarios Extension of the Collective Labour Agreement and Minority Unions}

Lo descrito anteriormente es crucial en la medida de que, al encontrase plasmada en cuerpo normativo, se confiere un nivel superior de protección al punto de considerarlas como derechos fundamentales, que en palabras del profesor Ferrajoli son:

"derechos subjetivos que corresponden universalmente a 'todos' los seres humanos en cuanto dotados del status de personas, de ciudadanos o personas con capacidad de obrar; entendiendo por 'derecho subjetivo' cualquier expectativa positiva (de prestaciones) o negativa (de no sufrir lesiones) adscrita a un sujeto por una norma jurídica; y por 'status' la condición de un sujeto, prevista asimismo por una norma jurídica positiva, como presupuesto de su idoneidad para ser titular de situaciones jurídicas y/o autor de los actos que son ejercicio de éstas" $(2004,37)$.

Como se aprecia, el DCT tiene tal relevancia en la sociedad que nuestra Constitución las ha considerado como necesario e imprescindible para la búsqueda de un Estado Social de Derecho fundamentado en el bienestar(2) y justicia social(3).

Asimismo, advertimos que esta consagración del DCT no es exclusiva de nuestra constitución actual, sino también se estaba desarrollada en la Constitución Política del Perú de 1979, específicamente en el artículo 54, que a pie de la letra mencionaba lo siguiente:

"Las convenciones colectivas de trabajo entre trabajadores y empleadores tienen fuerza de ley para las partes. El Estado garantiza el derecho a la negociación colectiva. La ley señala los procedimientos para la solución pacífica de los conflictos laborales. La intervención del Estado solo procede y es definitoria a falta de acuerdo entre las partes".

De esta manera, ambas constituciones, tanto de 1993 como la del 1979, consideran al DCT como un derecho fundamental cuyo ejercicio debe encontrarse garantizado. La única diferencia entre dichas constituciones recae en que la norma de 1979 considera al producto de la negociación colectiva: el convenio colectivo, bajo una jerarquía de rango legal. Mientras que, en el caso de la Constitución actual, no reconoce expresamente rango legal al convenio colectivo, por ende, se considera que tiene un rango menor al legal sin que ello suponga un menor reconocimiento en el plano jurídico.

\subsection{Derecho a la libertad sindical}

En base a esta consagración del DCT en nuestra Constitución, el Tribunal Constitucional (En adelante, "TC") ha procurado aplicarla e interpretarla de acuerdo a los pronunciamientos de la Organización Internacional del Trabajo (En adelante, "OIT") con la finalidad de estructurar su contenido constitucionalmente protegido y encontrar, cuando corresponda, mecanismos de protección de este derecho con la finalidad de garantizar su adecuado ejercicio por parte de los trabajadores.

En efecto, como se ha podido evidenciar a partir de nuestro CPP, el DCT es uno de naturaleza compleja, dado que engloba a tres derechos fundamentales: i) el derecho a la libertad sindical, ii) el derecho a la negociación colectiva, y iii) el derecho a la huelga.

En este acápite, nos referiremos al derecho de libertad sindical, y que es definida por el TC en el expediente No. 0008-2005-Al como la capacidad autoderminativa para participar en la constitución y desarrollo de la actividad sindical. Adicionalmente, la misma resolución del TC añade que:

"(La Libertad Sindical) implica un haz de facultades y el ejercicio autónomo de homus faver-homus politicus, referido a aspectos tales como:

(2) Ver Artículo 22 de la Constitución Política del Perú, "El trabajo es un deber y un derecho. Es base del bienestar social y un medio de realización de la persona".

(3) VerArtículo 44 del CPP: "Son deberes primordiales del Estado: defender la soberanía nacional; garantizar la plena vigencia de los derechos humanos; proteger a la población de las amenazas contra su seguridad; y promover el bienestar general que se fundamenta en la justicia y en el desarrollo integral y equilibrado de la Nación". 


\section{Jorge Toyama Miyagusuku y Alfredo Torres}

- El derecho a fundar organizaciones sindicales.

- El derecho de libre afiliación, desafiliación y reafiliación en las organizaciones sindicales existentes.

- El derecho a la actividad sindical.

- El derecho de las organizaciones sindicales a ejercer libremente las funciones que la Constitución y las leyes le asignen, en defensa de los intereses de sus afiliados. Ello comprende la reglamentación interna, la representación institucional, la autonomía en la gestión, etc.

- El derecho a que el Estado no interfiera -salvo el caso de violación de la Constitución o la ley- en las actividades de las organizaciones sindicales".

Asimismo, el TC, siguiendo con la mencionada sentencia, destaca que la libertad sindical se manifiesta en dos planos: el intuito persona y el plural. Respecto al primero, se plantean dos aspectos:

- Aspecto positivo: Comprende el derecho de un trabajador a constituir organizaciones sindicales y a afiliarse a los sindicatos ya constituidos. Dentro de ese contexto se plantea el ejercicio de la actividad sindical.

- Aspecto negativo: Comprende el derecho de un trabajador a no afiliarse o a desafiliarse de una organización sindical(4). Esta manifestación de la libertad sindical se desprende básicamente del artículo 8 del Protocolo Adicional en materia de Derechos Económicos, Sociales y Culturales, que consagra el derecho a no ser obligado a pertenecer a un sindicato, conforme se indicó anteriormente.
Mientras que en el caso de la libertad sindical plural se plantean tres aspectos:

- Ante el Estado: Comprende la autonomía sindical, la personalidad jurídica y la diversidad sindical.

- Ante los empleadores: Incluye el fuero sindical y la proscripción de prácticas desleales.

- Ante las otras organizaciones sindicales: Comprende la diversidad sindical, la proscripción de las cláusulas sindicales, etcétera.

De esta manera, se entiende que el Tribunal Constitucional se ha adscrito al pluralismo sindical, es decir, se permite que en una misma empresa exista más de un sindicato. Lo anterior, hace referencia a un modelo democrático de relaciones laborales que, lejos de ser una expresión genérica, implica lo siguiente:

"que los sujetos colectivos deban tener un papel protagónico, que tiene resonancias claras en la configuración democráticopluralista de la sociedad; puesto que, así como los partidos políticos son la expresión de la democracia política, las organizaciones sociales lo son del pluralismo social, lo que les permitirá hacer llegar sus demandas y velar por los intereses de los colectivos que representan incluso en la esfera política" (Villavicencio 2010, 48-9).

(4) Al respecto, se ha indicado: "En este marco general creemos necesario resaltar la ausencia de reconocimiento de la libertad sindical negativa, que sí se hallaba recogida en la Constitución de 1979 y lo está en todas las normas infraconstitucionales. Ello abre una posibilidad de que una posterior legislación pudiera admitir mecanismos como las cláusulas sindicales, cuya validez, en tanto productos de la autonomía colectiva, viene admitida por el Comité de Libertad Sindical.21 Partamos de señalar que esta facultad no está reconocida tampoco en el Convenio 87 de la OIT y hay quienes reclaman su establecimiento expreso para que sea exigible, como veremos posteriormente; aunque, en todo caso, la falta de tradición histórica de ese tipo de cláusulas convencionales en América Latina, con la excepción de Venezuela y México, conduce a relativizar tal posibilidad", en Alfredo Villavicencio, La libertad Sindical en el Perú: Fundamentos, alcances y regulación (Lima: OIT-PLADES, 2010), 55. 


\section{Extensión de los Convenios Colectivos de Trabajo y Sindicatos Minoritarios Extension of the Collective Labour Agreement and Minority Unions}

\section{Derecho a la libertad sindical (Neves 2016, 9)}

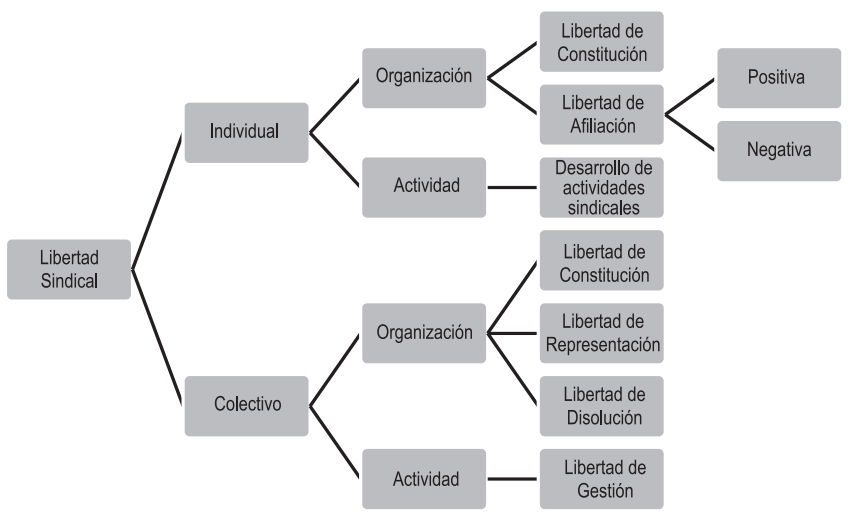

Por otro lado, en relación a la importancia que la OIT le ha otorgado al derecho de libertad sindical, es resaltante que este derecho se encuentra desarrollado en el Convenio 87, sobre la libertad sindical y la protección de la sindicación; en el Convenio 98, sobre el derecho de sindicación y de negociación colectiva; en el Convenio 135, sobre protección y facilidades a los representantes de los trabajadores en la empresa (no está ratificado por el Perú); y el Convenio 151, sobre protección del derecho de sindicación y los procedimientos para determinar las condiciones de empleo en la Administración Pública.

Estos convenios de la OIT, al versar sobre derechos fundamentales, tienen nivel constitucional y las interpretaciones de la OIT (Comité de Libertad Sindical, Comité de Expertos en la Aplicación de Convenios y Recomendaciones) tienen el mismo rango. En materia de libertad sindical, usualmente se describen estas manifestaciones (Villavicencio 2010, 69):

a) Derecho de los trabajadores, sin ninguna distinción, de constituir las organizaciones que se estimen conveniente, sin autorización previa (artículo 2 del Convenio 87).

b) Derecho de los trabajadores, sin ninguna distinción, de libre afiliación (artículo 2 del Convenio 87).

c) Derecho de las organizaciones de libre estructuración interna: redacción de estatutos y reglamentos, elección libre de sus representantes, organización de administración, actividades y programa de acción; materias en las que además se ordena la abstención estatal (artículo 3 del Convenio 87).

d) Derecho de las organizaciones de obtener personería jurídica sin condiciones limitativas (artículo 7 del Convenio 87).

e) Derecho de las organizaciones a no ser disueltas administrativamente (artículo 4 del Convenio 87).

f) Derecho de las organizaciones a constituir federaciones y confederaciones, nacionales e internacionales, con las mismas garantías que la constitución de organizaciones de base (artículo 5 del Convenio 87).

g) Obligación estatal de adoptar todas las medidas necesarias y apropiadas para garantizar el libre ejercicio del derecho de sindicación (artículo 11 del Convenio 87).

h) Derecho de los trabajadores a una adecuada protección contra cualquier discriminación por razones sindicales: fuero sindical (artículo 1 del Convenio 98).

i) Derecho de las organizaciones de trabajadores y empleadores a una adecuada protección contra actos de injerencia de unas sobre las otras (artículo 2 del Convenio 98).

j) Y obligación estatal de promover la negociación colectiva cuando sea ello sea necesario (artículo 4 del Convenio 98).

Asimismo, el derecho a la libertad sindical reviste de tal relevancia que, a raíz de la 86 Conferencia Internacional del Trabajo de la OIT, se aprobó la Declaración de la OIT relativa los principios y derechos fundamentales en el trabajo. Dicha Declaración sostiene que todos los miembros de la OIT, aun cuando no hayan ratificado los convenios aludidos, tienen un 
Jorge Toyama Miyagusuku y Alfredo Torres

compromiso que se deriva de su mera pertenencia a dicha organización de respetar, promover y hacer realidad, de buena fe y de conformidad con la Constitución, los principios relativos a los derechos fundamentales que son objeto de esos convenios, es decir, tienen el deber de proteger y efectivizar la libertad de asociación y la libertad sindical y el reconocimiento efectivo del derecho de negociación colectiva, y también los demás derechos laborales fundamentales como son los siguientes: a) la eliminación de todas las formas de trabajo forzoso u obligatorio; b) la abolición efectiva del trabajo infantil; y c) la eliminación de la discriminación en materia de empleo y ocupación.

\subsection{Derecho a la negociación colectiva: contenido y eficacia}

Luego de haber desarrollado el contenido constitucionalmente protegido del derecho a la libertad sindical, continuaremos ahora con el desarrollo del derecho a la negociación colectiva.

En primer lugar, debemos mencionar que "el fundamento principal de la existencia de la negociación colectiva como proceso y del convenio colectivo como producto mismo, es la necesidad de equilibrar la situación dispar existente entre los trabajadores y el empleador" (Ganoza 2017, 7). En otras palabras, la convención colectiva constituye un instrumento idóneo para viabilizar la promoción de la armonía laboral, así como para conseguir un equilibrio entre las exigencias sociales de los trabajadores y la realidad económica de la empresa (Ganoza 2017, 7).

En términos del TC, se define al Convenio Colectivo (también denominado contrato de paz social, acuerdo corporativo, pacto de trabajo) como:

"el acuerdo que permite crear, modificar o extinguir derechos y obligaciones referidas a remuneraciones, condiciones de trabajo, productividad y demás aspectos concernientes a las relaciones laborales. En puridad, emana de una autonomía relativa consistente en la capacidad de regulación de las relaciones laborales entre los representantes de los trabajadores y sus empleadores"
(Tribunal Constitucional 2005, fundamento jurídico 29).

Ahora bien, con relación al contenido de los convenios colectivos, debemos advertir que aun cuando las cláusulas remunerativas son muy generalizadas en los acuerdos, no es lo único que se puede pactar, convenir o negociar en un convenio colectivo.

En efecto, de acuerdo con el artículo 2 Convenio 154 de la OIT sobre la negociación colectiva, se indica las cláusulas que se pueden pactar -no de forma limitativa, sino más bien extensiva- en un convenio colectivo son las siguientes:

"A los efectos del presente Convenio, la expresión negociación colectiva comprende todas las negociaciones que tienen lugar entre un empleador, un grupo de empleadores o una organización o varias organizaciones de empleadores, por una parte, y una organización o varias organizaciones de trabajadores, por otra, con el fin de:

(a) fijar las condiciones de trabajo y empleo, o

(b) regular las relaciones entre empleadores $y$ trabajadores, o

(c) regular las relaciones entre empleadores o sus organizaciones y una organización o varias organizaciones de trabajadores, o lograr todos estos fines a la vez".

Asimismo, el Ministerio de Trabajo y Promoción del Empleo establece algunas materias generales que podrían ser parte de un Convenio Colectivo, claro está sin ánimos de ser taxativa ${ }^{(5)}$ :

(5) Véase Informe No. 039-2012-MTPE/2/14, de fecha 12 de octubre de 2012, emitido por la Dirección General de Trabajo del MTPE. Asunto: Consulta se refiera a la aplicación de un convenio colectivo de eficacia limitada a los trabajadores no sindicalizados. 


\section{Extensión de los Convenios Colectivos de Trabajo y Sindicatos Minoritarios Extension of the Collective Labour Agreement and Minority Unions}

a) La relación de cambio entre trabajo y salario: los contenidos propios del terreno de la distribución (salario, jornada, descansos, premios, indemnizaciones, etcétera).

b) El área de las relaciones de producción, principalmente, la organización del proceso productivo (...).

c) Las relaciones colectivas entre empresarios y trabajadores: dirigidas a regular las relaciones entre sujetos colectivos.

d) La actuación de la empresa como sujeto económico: no desde el punto de vista estricto de las relaciones laborales, sino en la actividad de la empresa como organización económica para la producción y el cambio de mercancías.

e) La situación social de los trabajadores: la que se deriva de su condición objetiva en el proceso productivo.

De lo mencionado hasta este momento, se puede advertir que existen tres tipos de cláusulas que se pactan en un convenio colectivo: cláusulas normativas, cláusulas obligacionales y cláusulas delimitadoras. Las primeras se incorporan automáticamente a los contratos individuales de trabajo y los que aseguran o protegen su cumplimiento; las segundas, son aquellas que establecen derechos de naturaleza colectiva laboral entre las partes del convenio; y finalmente, con relación a las cláusulas delimitadoras, estas son aquellas que versan sobre el ámbito y vigencia del convenio.

En este sentido, para la adecuada interpretación de cada una de las cláusulas, es necesario entender que cada una se interpreta de manera distinta. Por ejemplo, en el caso de las cláusulas normativas, estas

"deben ser interpretadas como norma jurídica, pues su aplicación no se reduce a las partes contractuales, sino que afectan a las relaciones individuales de trabajo, no solo de los que son trabajadores o miembros del sindicato en la actualidad, sino a los que se van a incorporar a dichas categorías con posterioridad mientras dichas cláusulas se encuentren vigentes" (Ganoza 2017, 9).

Mientras que, en el caso de las cláusulas obligacionales, estas "tienen como objeto regular la relación entre las partes que suscriben dicho convenio, por lo tanto, las mismas deben ser interpretadas de acuerdo con las normas sobre contratos" (Ganoza 2017, 9).

Por otro lado, en referencia a la eficacia de los convenios colectivos, las distintas cláusulas mencionadas se someten a lo establecido por el inciso 2 del artículo 28 de la Constitución cuando señala que las convenciones colectivas tienen fuerza vinculante en el ámbito de lo concertado. En tal sentido, la fuerza vinculante en el ámbito de lo concertado obliga:

- A las personas celebrantes de la convención colectiva.

- A las personas representadas (o representatividad) en la suscripción de la convención colectiva.

- A las personas que se incorporen con posterioridad a la celebración de la convención colectiva.

Este artículo 28 de la Constitución ha sido desarrollado en el fundamento 33 de la sentencia del TC No. 0008-2005-Al que indica lo siguiente:

"Esta noción (ámbito vinculante en el ámbito de lo concertado) se la concibe como referente del carácter normativo del acuerdo laboral. Tal como refiere Javier Neves Mujica, [Introducción al derecho laboral. Lima; PUCP, 2003], esto implica la aplicación automática de los convenios colectivos a las relaciones individuales comprendidas en la unidad negocial correspondiente, sin que exista la necesidad de su posterior recepción en los contratos individuales, así como su relativa imperatividad frente a la autonomía individual, la que sólo puede disponer su mejora, pero no su disminución." 
Jorge Toyama Miyagusuku y

Alfredo Torres

Adicionalmente, el fundamento 31 de la sentencia antes mencionada se desprende que "la fuerza vinculante [del convenio colectivo] implica que en la convención colectiva las partes pueden establecer el alcance y las limitaciones o exclusiones que autónomamente acuerden con arreglo a ley" (Tribunal Constitucional 2005, fundamento jurídico 31). Es claro entonces que las partes del convenio colectivo podrán establecer los alcances del convenio colectivo, posibilitando así incluso la extensión del convenio a los no sindicalizados. Sobre esto último, en el siguiente acápite, nos referiremos realizando el desarrollo legal de la negociación colectiva en el Perú, haciendo hincapié que no excluye la posibilidad de que los convenios puedan ser extendidos a los trabajadores no afiliados.

\section{Convenio Colectivo: eficacia personal general y limitada}

Antes de entrar a desarrollar sobre la eficacia de los convenios colectivos, señalaremos en primer lugar dos conceptos básicos para entender los efectos del convenio colectivo: Capacidad negocial y Legitimidad negocial.

Para clarificarnos el panorama, el profesor Neves Mujica señala la diferencia entre estos dos conceptos:

"para que un convenio tenga eficacia personal general se requiere que la organización sindical pactante posea legitimidad negocial, que es la aptitud específica para celebrar convenios colectivos de ese alcance y se adquiere en nuestro ordenamiento cuando se afilia a la mayoría absoluta de trabajadores del ámbito en el que se desarrolla la negociación y al cual se aplicará el convenio", en cambio la capacidad negocial es "la aptitud genérica para celebrar convenios colectivos" (Neves 2009, 90-1).

De esta manera, se entiende por capacidad negocial a la facultad inherente a toda organización sindical para que sea participe de una negociación colectiva. Mientras que, en el caso de la legitimidad negocial, esta es definida como la aptitud específica para ser parte en una negociación colectiva y suscribir el convenio colectivo con el empleador (Ganoza 2017, 10).

Esta diferenciación radica en que nuestro país, al haber asumido el sistema de pluralidad sindical, es necesario que exista una eficacia de los convenios colectivos con la finalidad de que los beneficios de dicho convenio suscrito por el sindicato que cuenta con legitimidad sindical puedan incidir en los demás trabajadores que no se encuentran afiliados.

En base a lo anterior, nuestra legislación ha determinado los efectos de la negociación colectiva. Por un lado, el convenio colectivo atribuye efectos generales en caso el sindicato agrupe a la mayoría de los trabajadores del ámbito (sindicato más representativo, siempre que afilie a la mitad más uno de los trabajadores como mínimo): empresa, rama de actividad o gremio. Por otro lado, en caso el sindicato minoritario, es decir aquel que agrupe a menos de la mayoría de trabajadores, la eficacia es limitada para los efectos del convenio colectivo; en otras palabras, las cláusulas solo serán aplicables a los trabajadores que conforman el sindicato.

De acuerdo con nuestra legislación, el artículo 9 del Texto Único de la Ley de Relaciones Colectivas de Trabajo, aprobado por el Decreto Supremo N ${ }^{\circ}$ 010-2003-TR (En adelante, "LRCT"), establece una eficacia personal general de las cláusulas del convenio colectivo, en la medida que señala:

"En materia de negociación colectiva, el sindicato que afilie a la mayoría absoluta de los trabajadores comprendidos dentro de su ámbito asume la representación de la totalidad de los mismos, aunque no se encuentren afiliados. De existir varios sindicatos dentro de un mismo ámbito, podrán ejercer conjuntamente la representación de la totalidad de los trabajadores los sindicatos que afilien en conjunto a más de la mitad de ellos".

Bajo el mismo concepto, el artículo 34 del Reglamento de la LRCT menciona también que: 


\section{Extensión de los Convenios Colectivos de Trabajo y Sindicatos Minoritarios Extension of the Collective Labour Agreement and Minority Unions}

\begin{abstract}
"La representación de todos los trabajadores del respectivo ámbito, a excepción del personal de dirección y de confianza, será ejercida por el sindicato cuyos miembros constituyan mayoría absoluta respecto del número total de trabajadores del ámbito correspondiente. (...) Los sindicatos que en conjunto afilien a más de la mitad de los trabajadores del respectivo ámbito, podrán representar a la totalidad de tales trabajadores a condición de que se pongan de acuerdo sobre la forma en que ejercerán la representación de sus afiliados. De no existir acuerdo sobre el particular, cada uno de ellos sólo representará a sus afiliados".
\end{abstract}

En otras palabras, la eficacia personal general bajo nuestra legislación laboral peruana requiere que el sindicato cuente con una representatividad, constituida por la mayoría absoluta de los trabajadores que se encuentren afiliados al sindicato. Esta puede darse a partir de que un único sindicato cuenta con dicha representatividad o cuando los sindicatos minoritarios decidan agruparse y participar como un solo grupo, en este caso también deberán contar con la mayoría absoluta.

Por otro lado, respecto a la eficacia personal limitada, el último párrafo del artículo 9 de la LRCT señala que: "los sindicatos determinarán la forma en que ejercerán esa representación, sea a prorrata, proporcional al número de afiliados, o encomendada a uno de los sindicatos. De no haber acuerdo, cada sindicato representa únicamente a sus afiliados". Asimismo, el segundo párrafo del artículo 34 del Reglamento de la LRCT indica que: "En el caso que ningún sindicato de un mismo ámbito afilie a la mayoría absoluta de trabajadores de éste, su representación se limita a sus afiliados".

Debemos advertir entonces que las partes, al momento de la negociación colectiva, deberán establecer si el sindicato negociador es uno que cuenta con legitimidad negocial o no. Ello es importante como hemos venido desarrollando a lo largo del presente acápite, dado que si el sindicato cuenta con legitimidad negocial (o representatividad) los acuerdos al que arriben tendrán una eficacia personal general, es decir, el convenio colectivo (cláusulas normativas) será de aplicación a todos los trabajadores de la empresa, afiliados al sindicato mayoritario y a los no afiliados, y si en caso hubiera a los afiliados al sindicato minoritario.
Dicho esto, no es de extrañar que se considere que esta legitimidad negocial supuestamente contradice lo dispuesto por el artículo 42 de la LRCT. Sin embargo, ello no es cierto, dado que, como hemos puntualizado líneas arriba, considerando que nuestro ordenamiento acogió el sistema de pluralismo sindical, es necesario otorgar soluciones para que los trabajadores en su totalidad puedan ser beneficiados de los convenios colectivos, que de otra forma no podrían gozarlos, salvo que se cambie a un sistema de unicidad sindical, supuesto que no es el caso peruano. Además que, "si bien el sindicato mayoritario puede negociar colectivamente en representación de todos los trabajadores de un determinado ámbito, eso no impide que los sindicatos minoritarios puedan negociar aspectos específicos a favor de sus afiliados, debiendo en todo caso observar el convenio mayoritario a título de derecho mínimo necesario" (Ganoza 2017, 21).

En caso contrario, si el sindicato negociador no cuenta con la representatividad necesaria para tener legitimidad negocial, el convenio colectivo será limitado solo a los afiliados a dicho sindicato.

Aquí es necesario realizar una precisión, dado que puede confundirse dos supuestos distintos: i) por un lado, que la norma estipule que el sindicato minoritario negocia solo respecto a sus propios afiliados, ii) y, por otro, de que el empleador extienda a los no afiliados los beneficios provenientes del convenio colectivo suscrito con un sindicato minoritario.

Nos explicamos, la normativa legal que regula la eficacia del convenio colectivo no prohíbe que se extienda los acuerdos del convenio colectivo de un sindicato minoritario a los no afiliados. De tal manera, que, si se interpretase de esa manera, se contravendría el principio de legalidad y el inciso a) del literal 24 del artículo 2 de la Constitución que indica que: 


\section{Jorge Toyama Miyagusuku y}

Alfredo Torres

"Nadie está obligado a hacer lo que la ley no manda, ni impedido de hacer lo que ella no prohíbe".

En este sentido, la extensión de los convenios colectivos suscrito por un sindicato minoritario a los no sindicalizados per se no se debería considerarse prohibitivo, salvo que el empleador haya acordado con el sindicato minoritario la no extensión del convenio. Lo que debemos analizar entonces es si tal decisión empresarial de extensión de dicho convenio es vulneratorio de la libertad sindical. En otras palabras, se debe probar el daño o afectación que se genera a la libertad sindical del sindicato minoritario, por ejemplo, a través de acreditar que tal extensión generó directamente la desvinculación de afiliados del sindicato minoritario o actos de coacción en contra de los afiliados para que se desafilien ${ }^{(6)}$.

La postura antes mencionada, es también señalada por la OIT cuando indica que:

"cuando en un proceso de negociación con el sindicato, la empresa ofrece simultáneamente mejoras en las condiciones de trabajo a los trabajadores no sindicalizados a través de convenios individuales existe un peligro serio de que se menoscabe la capacidad negociadora del sindicato y que se produzcan situaciones discriminatorias que favorezcan al personal no sindicalizado; además, ello puede promover la desafiliación de trabajadores sindicalizados" [énfasis agregad] (OIT 2006, párrafo 1054).

Respecto a la cita anterior, no negamos que exista un peligro latente de que se vulnere la libertad sindical del sindicato minoritario tanto en su esfera individual como plural; sin embargo, ese peligro debe ser claramente identificado y probado. Ello se aprecia en la medida que la OIT menciona que este hecho materia de discusión "puede' promover la desafiliación de trabajadores sindicalizados", es decir, la OIT no es determinante en asegurar que existiría una afectación a la libertad sindical en caso se extienda el convenio colectivo a los no afiliados. De tal manera que, para asegurar la vulneración, esta debe ser probada como es necesario en caso de una demanda de indemnización por daños y perjuicios.

La mera extensión a los trabajadores no sindicalizados de un convenio colectivo suscrito con un sindicato minoritario no es inconstitucional. No existe norma que impida dicha extensión y, más bien, al amparo de la libertad de empresa, se debería permitir la aplicación de un convenio colectivo, salvo que se aprecie que, fruto de la extensión, se perjudique al sindicato (como puede ser la desafiliación de trabajadores del sindicato tras la extensión del convenio).

Si se impide la extensión del convenio colectivo, se tendría que permitir que el empleador otorgue beneficios a los trabajadores no sindicalizados, pero, cuando ello ha ocurrido, se señala que es anti sindical. Es decir, se afecta los trabajadores sindicalizados y al sindicato si una empresa entrega mayores o mejores beneficios a los trabajadores que no pertenecen a un sindicato, calificándose la conducta del empleador como antisindical.

De esta forma, se debe admitir la posibilidad de que el empleador pueda extender el convenio colectivo a los trabajadores no sindicalizados. No se trata de una obligación de extensión, es una facultad del empleador.

(6) Respecto este tema, es necesario describir sobre la carga de la prueba. Es en este sentido que la Nueva Ley Procesal del Trabajo se ocupa de la carga de la prueba en el artículo 23, regulación que, a nuestro criterio, reivindica el principio de inversión de la carga de la prueba, de tal forma que el citado principio se convierte en una medida tendente a equilibrar a las partes que intervienen en el proceso, pues, como sabemos, una de las manifestaciones del desequilibrio innato entre las partes de la relación laboral es la desigualdad probatoria. En efecto, desde el momento en que la relación laboral se lleva a cabo en el lugar indicado por el empleador, éste tiene mayores y mejores posibilidades de premunirse de medios probatorios que le servirán en un eventual conflicto jurídico. En ese sentido, resulta necesario que la norma procesal laboral contenga disposiciones que tiendan a superar este desequilibrio. Al respecto, puede verse Toledo Toribio, Omar. 2012. Los principios de la actividad jurídico. Suplemento de análisis legal de El Peruano, martes 6 noviembre. 


\section{Extensión de los Convenios Colectivos de Trabajo y Sindicatos Minoritarios Extension of the Collective Labour Agreement and Minority Unions}

En efecto, si solo los afiliados al sindicato tendrían derecho a los incrementos remunerativos pactados en los convenios colectivos en desmedro de los no afiliados, es claro que con la finalidad de brindar mayores beneficios a los afiliados se desproteja el derecho de libertad sindical negativa de los trabajadores. En otras palabras, los trabajadores no afiliados tienen derecho a incrementos remunerativos al igual que los trabajadores afiliados lo tienen a través de los convenios colectivos.

De esta manera, es incongruente que por un lado se niegue la extensión del convenio colectivo a los no afiliados y, por otro lado, se prohíba otorgar beneficios remunerativos solo a los no afiliados considerando que es en desmedro de los sindicalistas. Bajo este escenario, nuestro sistema alentaría la ventaja patrimonial de un sindicalizado en perjuicio de un no sindicalizado, considerando que ambos trabajadores realizan las mismas labores y bajo las mismas condiciones. ¿Acaso existiría una superioridad del derecho a la libertad sindical positiva sobre la negativa?

En base a lo dicho hasta este momento, creemos oportuno desarrollar cuál es la postura que maneja los operadores del derecho respecto a este tema. En el siguiente acápite, describiremos los pronunciamientos respecto a nuestro tema de análisis del Tribunal Constitucional, de la Corte Suprema y de las resoluciones de la Superintendencia de Fiscalización Laboral (En adelante, "SUNAFIL").

\section{Jurisprudencia y pronunciamientos administrativos entorno a las extensiones de convenios colectivos}

En el presente acápite, analizaremos los pronunciamientos realizados por el Tribunal Constitucional, por la Corte Suprema y por la SUNAFIL en relación con la extensión de los convenios colectivos suscritos con los sindicatos minoritarios a los trabajadores no sindicalizados.

\subsection{Tribunal Constitucional: ¿contradicción de sentencias?} El Tribunal Constitucional tuvo la oportunidad de pronunciarse sobre la legalidad de la extensión de los convenios colectivos; sin embargo, como se apreciará el TC tuvo dos posiciones que podrían tener sentidos opuestos, pero, como veremos, no son contradictorias. La primera de las sentencias recayó en el expediente No. 02476-2010PA/TC (conocida por sentencia "Gloria"), tuvo como fecha de pronunciamiento el día 24 de octubre de 2011; mientras que la segunda sentencia controversial recayó en el expediente No. 02974-2010-PA/TC (conocida por sentencia "Alicorp") esta fue emitida el día 2 de noviembre de 2011.

Es necesario advertir, que en ambas sentencias en rigor no se discute la extensión de los convenios colectivos, sino más bien se encuentra referida a determinar si la práctica de la empresa al momento de negociar un convenio colectivo con el sindicato y que al mismo tiempo otorga beneficios económicos a los no afiliados es atentatoria a la libertad sindical positiva, la cual es analizada a la luz de si existe o no daño a dicha libertad sindical, la misma que deberá ser plenamente probada.

4.1.1. STC No. 2476-2010-PA/TC (sentencia de Gloria)

En este proceso se discutió la demanda interpuesta por el sindicato de Gloria S.A. que solicitó lo siguiente: i) la aplicación de los derechos a la igualdad ante la ley y a la no discriminación, ii) se haga extensivo el pago a cuenta de reintegros por el incremento de remuneraciones de su Pliego de Reclamos del año 2007 que la sociedad emplazada ha otorgado al personal obrero no sindicalizado, iii) que todo incremento bajo cualquier modalidad que se otorgue al personal obrero no sindicalizado durante los años 2007 y 2008 se haga también extensivo al personal obrero sindicalizado, y iv) que la sociedad demandada se abstenga de incentivar y promover la desafiliación de sus afiliados, mediante el otorgamiento de beneficios económicos y/o condiciones de trabajo al personal no sindicalizado.

La empresa Gloria sostuvo que no tiene responsabilidad en que se haya generado desafiliaciones internas de algunos afiliados 
Jorge Toyama Miyagusuku y Alfredo Torres

del organismo sindical, sino que ello se debe al accionar errado de la dirigencia sindical.

En el proceso se acreditó que la empresa decidió entregar un adelanto a cuenta del incremento de remuneraciones del año 2007 al personal obrero no sindicalizado. Mientras la empresa realizaba estos actos también se encontraba negociando el pliego de reclamos con el sindicato. De esta manera, el TC indicó que el ofrecimiento de la Sociedad emplazada conllevó a desestimular la actividad sindical y por ello que varios trabajadores procedieron a presentar sus cartas de desafiliación a la organización sindical encontrándonos ante la vulneración al derecho de sindicalización de los trabajadores del sindicato recurrente, corresponde estimar la demanda.

Asimismo, el TC expresó que no encuentra una justificación razonable para otorgar beneficios económicos a los trabajadores no sindicalizados y excluir a los sindicalizados, toda vez que, al ser trabajadores de una misma empresa, merecen un trato igual, bajo las mismas condiciones, por lo que claramente se demuestra una afectación al derecho de igualdad y a una discriminación en orden al carácter sindical de los trabajadores que integran el sindicato, al no otorgárseles las mismas condiciones; de este modo, se evidencia de la sentencia que existe la probanza del daño generado a la libertad sindical positiva de los trabajadores del sindicato.

Como se aprecia, entonces, en el presente proceso, la empresa realizó simultáneamente un acto unilateral de ofrecimiento de incremento remunerativo a los no afiliados al sindicato y, por otro lado, negoció con dicho sindicato. Contexto que genera, y se encuentra acreditado, una desafiliación a la organización sindical.

Lo interesante de esta sentencia, que a diferencia a de la de Alicor, como se apreciará, es que en este proceso es necesario darle importancia al momento en el cual se realiza el acto unilateral del empleador de otorgar beneficios a los no afiliados. Es claro, que se vulnera la libertad sindical de los afiliados al sindicato (ámbito de libertad sindical plural), toda vez que el empleador desincentiva la afiliación al otorgar incremento remunerativo, los cuales justamente estaban siendo negociados por dicho sindicato, el cual se materializaría después de haber otorgado dichos beneficios a los no sindicalizados.
4.1.2. STC No. 2974-2011-PA/TC (sentencia Alicorp)

En este proceso, el sindicato recurrente interpuso demanda de amparo contra la empresa Alicorp S.A.A. solicitando que se ordene la nivelación de las remuneraciones, jornales y cualquier otro tipo de beneficio de carácter laborales de los trabajadores sindicalizados y la suspensión inmediata de todo acto o mecanismo que afecte la afiliación de los trabajadores, como es el premiar a éstos por renunciar al sindicato. Por el otro lado, la empresa señaló que es falso que haya efectuado una política de discriminación salarial o de beneficios laborales entre sus trabajadores. Manifiesta, asimismo, que no tiene responsabilidad en la renuncia de los trabajadores al sindicato, ya que no ha realizado actividades antisindicales.

Ante ello, las dos instancias inferiores determinaron que no se desprende la existencia de un trato remunerativo discriminatorio entre los trabajadores sindicalizados y los no sindicalizados, así como tampoco se puede inferir que la diferencia de los pagos a algunos trabajadores se deslinde de una actitud negativa de represalia como consecuencia de la afiliación al sindicato.

Finalmente, para el TC tanto los afiliados como lo no afiliados tuvieron incrementos remunerativos de distinta fuente, negociación colectiva y política de la empresa, respectivamente. De esta manera, se advirtió que la empresa no efectuó una medida arbitraria, irrazonable o desproporcionada al otorgar beneficios remunerativos a los no afiliados. Asimismo, el TC señaló que los trabajadores que se desafiliaron al sindicato ejercieron su libertad sindical, tanto individual como plural, por lo cual optaron voluntariamente por la desafiliación como miembros del sindicato, no habiéndose acreditado durante el proceso que la emplazada haya coaccionado de modo alguno a aquellos trabajadores que 


\section{Extensión de los Convenios Colectivos de Trabajo y Sindicatos Minoritarios Extension of the Collective Labour Agreement and Minority Unions}

optaron por no continuar en el sindicato. Nuevamente como se aprecia, el TC analiza la existencia o no de vulneración de la libertad sindical positiva, señalando claramente que esta no existe en el presente caso.

Efectivamente, la sentencia del TC sostuvo que no se ha vulnerado la libertad sindical individual positiva, la cual claramente indica que tampoco se afectó la libertad sindical colectiva del sindicato, en tanto no se ha probado que Alicorp haya coaccionado a los trabajadores para que se desafilien del sindicato. Por el contrario, se mencionó en la sentencia, que la desafiliación es producto de la decisión del propio trabajador de desvincularse, derecho que se encuentra protegido por el derecho a la libertad sindical negativa que el TC ha desarrollado y que los instrumentos internacionales también lo han descrito, por ejemplo, en el artículo 8 del Protocolo Adicional en materia de Derechos Económico, Sociales y Culturales, en la cual se menciona textualmente que "nadie podrá ser obligado a pertenecer a un sindicato".

En consecuencia, luego de haber resumido ambas sentencias del TC, se aprecia con mayor claridad que dichas sentencias tienen supuestos de hechos distintos y, por tanto, conclusiones distintas también. Por ende, no guardan ninguna contradicción sobre la materia que venimos reflexionando. En otras palabras, para acreditar la vulneración a la libertad sindical no basta con indicar que el convenio colectivo suscrito por un sindicato minoritario se extendió a los no afiliados, sino que se deberá probar tal vulneración, acreditando pagos por renuncias al sindicato, coacción para la desafiliación, supuestos de vulneración al principio de igualdad, etcétera.

\subsection{Corte Suprema: ¿mantiene una postura definida?}

En materia de negociación colectiva, la Corte Suprema ha emitido sentencias variadas que sostienen una postura a favor de la extensión de convenios colectivos o, por el contrario, cambiaban todo el criterio asumido hasta ese momento. A continuación, resumiremos las casaciones laborales más importantes y recientes.

\subsubsection{Casación Laboral No. 2864-2009-Lima}

En el presente proceso, seguido por el señor Aristes Peña Ríos, trabajador no afiliado de la empresa Compañía Universal Textil S.A., se solicitó la extensión y pago de los beneficios económicos otorgados por las convenciones colectivas de trabajo correspondientes a los períodos 1994 y 1995, a aquellos trabajadores no afiliados al sindicato minoritario suscribiente de los citados acuerdos.

Ante ello, la Corte Suprema realizó una interpretación de los artículos 9 y 42 de la $\mathrm{LRCT}$, referido a que un sindicato minoritario representa únicamente a sus afiliados y por tanto sus efectos solo recaen en estos, con el principio de igual señalado en el inciso 2 del artículo 2 de la CPP.

De esta manera, la Corte Suprema señaló que, en base al principio de igualdad, el artículo 42 debe interpretarse de tal manera que su fórmula no es limitativa sino abierta para la eficacia del acuerdo colectivo, tanto así que considera con los mismos efectos al caso de los trabajadores que no formaron parte del sindicato minoritario que celebró el convenio con aquellos trabajadores que con posterioridad a la celebración del convenio se incorporaron a la organización sindical.

La Corte Suprema sostuvo que se debía extender el convenio colectivo de trabajo, no se trataba de una facultad del empleador. De tal forma que, la Corte Suprema en este proceso decidió otorgar al trabajador no sindicalizado los incrementos económicos acordados en los convenios suscritos por el sindicato minoritario.

4.2.2. Casación Laboral No. 10766-2013-Moquegua

El proceso laboral es seguido por el Sindicato Unificado de Trabajadores SPCC-Ilo contra la empresa Southern Perú Cooper Corporation Sucursal del Perú, en la cual aquella solicitó la extensión de los beneficios económicos que versan sobre bonificaciones extraordinarias y bonificaciones liberales, las mismas que son abonadas a los trabajadores de otros sindicatos (Sindicato de Trabajadores Obreros de SPCC, el Sindicato de Empleadores de la Refinería de Cobre llo) y no sindicalizados y, 
Jorge Toyama Miyagusuku y Alfredo Torres

además, solicitó que la empresa demandada se abstenga en incurrir en actos discriminatorios que menoscaben las remuneraciones y la dignidad de los trabajadores afiliados al sindicato demandante.

En primera instancia, de declaró infundada la demanda, es decir, la empresa no deberá pagar ningún monto solicitado al sindicato demandante. Sin embargo, en segunda instancia, la Sala determinó que las bonificaciones no corresponden a la versión dada por la empresa, la misma que consistía en compensar los ingresos en relación al sindicato demandante (bolsa de cierre), toda vez de ser así se debió estipularse de esa forma; entonces, al haberse otorgado como consecuencia de una decisión voluntaria de la empresa debe hacerse extensiva a los afiliados del sindicato demandante en virtud del principio de igualdad pues resulta un acto discriminatorio el hecho de dar bonificaciones a trabajadores que desempeñan las mismas funciones sin justificación objetiva ni razonable, vulnerando así el artículo 2 inciso 2 de la CPP, referido al principio de igualdad.

En base a lo descrito, la empresa interpuso el recurso de casación. Es así como, en dicho proceso se determinó que no existen diferencias económicas entre los trabajadores afiliados al sindicato demandante, el Sindicato de Trabajadores Obreros de SPCC, el Sindicato de Empleadores de la Refinería de Cobre llo y los trabajadores no sindicalizados, mucho menos discriminación, dado que todos estos sindicatos y los no afiliados recibieron por parte de la empresa durante el periodo 2006-2012 la misma cantidad de dinero ascendente a S/ 27,000.00.

Por ende, se declaró fundado el recurso de casación, confirmando así la sentencia de primera instancia que declara infundada la demanda, con lo cual la empresa no deberá hacer efectivo los beneficios económicos solicitados por el sindicato demandante. Nótese en este caso que, si hubiera alguna diferencia en los beneficios percibidos, aparentemente la Corte Suprema habría declarado fundada la demanda de los trabajadores que solicitaban la extensión del convenio colectivo.

4.2.3. Casación Laboral No. 12901-2014-Callao

En el presente proceso laboral, la señora María del Carmen Vásquez Ugas de Jáuregui, apoderada de los demandantes Gladys Elizabeth Torres Pohl de Rodríguez y otros, pretendía el pago por concepto de reintegro del haber básico otorgado por el Laudo Arbitral del año 2010, suscrito entre la demandada y el Sindicato Nacional Unificado de Trabajadores de CORPAC S.A. (SITE - CORPAC), quien a esa fecha era sindicato minoritario.

En primera instancia, se declaró infundada la demanda, bajo el argumento que no existe razón objetiva para que se le otorgue a la accionante los beneficios establecidos en el Laudo Arbitral, toda vez que no fueron parte de la negociación colectiva del sindicato con la demandada, ni el citado sindicato ejerció representatividad sindical respecto de ellos.

Por otro lado, la Sala Laboral, revocó la sentencia de primera, declarando fundada la demanda, luego de considerar que, al tener los derechos reclamados el carácter de permanente, corresponde que sean percibidos por los demandantes a partir de la fecha de afiliación al sindicato.

Ahora bien, llegado el proceso a la Corte Suprema, el máximo órgano del Poder Judicial señaló que, al tratarse de sindicato minoritario, mediante Laudo se resolvió otorgar beneficios a los trabajadores sujetos a la negociación colectiva. En tal sentido, se puede inferir que el ámbito de aplicación personal de dicho laudo arbitral se circunscribe, coherentemente, a los afiliados de dicho sindicato, esto es, nos encontramos ante un convenio colectivo de eficacia limitada; por lo tanto, los beneficios señalados en el laudo arbitral serán de aplicación sólo para los afiliados al sindicato, así como los que se incorporen con posterioridad.

De esta manera, la sentencia de la Corte Suprema determinó como principios jurisprudenciales de obligatorio cumplimiento respecto a la interpretación judicial sobre la representatividad sindical lo siguiente: 


\section{Extensión de los Convenios Colectivos de Trabajo y Sindicatos Minoritarios Extension of the Collective Labour Agreement and Minority Unions}

\begin{abstract}
"Lo discernido anteladamente permite concluir que cuando el convenio colectivo ha sido celebrado por una organización sindical de representación limitada, la misma que no goza de la representatividad de la mayoría de los trabajadores no puede extenderse los efectos del convenio colectivo de este sindicato a los no afiliados del mismo, pues, permitirlo desalentaría la afiliación en tanto los trabajadores preferirían no afiliarse a una organización sindical, pues de igual modo gozarían de los beneficios pactados en los convenios colectivos que celebre dicho sindicato".
\end{abstract}

\subsubsection{Casación Laboral No. 16995-2016-Lima}

En la presente casación laboral, la Corte Suprema resuelve el proceso laboral iniciado por Charlly Sánchez Valencia en contra del Banco de la Nación, en la cual se solicitó que se declare la desnaturalización de los contratos de locación de servicios suscritos y que se reconozca la existencia de una relación laboral a plazo indeterminado. Además de ello, el pago de incremento de convenios colectivos y laudos arbitrales.

En primera instancia, el Décimo Primer Juzgado de Trabajo Permanente de la Corte Superior de Justicia de Lima declaró fundada en parte la demanda, incluido el pago por los conceptos del convenio colectivo y el laudo arbitral. Asimismo, en segunda instancia, la Cuarta Sala Laboral confirmó la sentencia de primera.

En este contexto, el Banco de la Nación interpuso recurso de casación, ante lo cual la Corte Suprema determina lo siguiente, sin contradecir los principios jurisprudenciales de obligatorio cumplimiento de la Casación Laboral No. 12901-2014-LIMA:

Si bien un convenio colectivo celebrado por una organización sindical minoritaria, no puede extender sus efectos a los no afiliados, pues se requiere la mayor representatividad sindical; sin embargo, este supuesto de hecho no puede aplicarse a los trabajadores que formalmente estuvieron bajo contratos de naturaleza civil y posteriormente, en proceso judicial, se reconoció su relación laboral, toda vez que se encontraban impedidos de ejercer su derecho constitucional a la libertad sindical positiva. En consecuencia, no resulta exigible a los demandantes que pretendan la percepción de los beneficios económicos plasmados en una convención colectiva, la acreditación de la representatividad del Sindicato que ha sido parte de la negociación colectiva.
Asimismo, se determinó que los efectos de un convenio colectivo celebrado por un Sindicato minoritario pueden ser extensivos a todos los trabajadores de la empresa, cuando dicha extensión se encuentre prevista en la convención, mediante una cláusula delimitadora, pues esta cláusula tiene la particularidad de establecer el ámbito de aplicación y los acuerdos del convenio, tienen fuerza vinculante para las partes que la adoptaron.

En este sentido, en el presente proceso, se reconoció al demandante un vínculo laboral a plazo indeterminado. Asimismo, se evidencia que, de las Actas de Negociación Colectiva y el Laudo Arbitral, suscritos por el Banco de la Nación y el Sindicato Nacional de Trabajadores del Banco de la Nación (SINATBAN) y del convenio suscrito entre la misma demandada con el Sindicato Nacional Amplio de Trabajadores del Banco de la Nación (SINATRABAN), que tales convenios rigen para todos los trabajadores que tengan vínculo laboral vigente incluido a los no sindicalizados.

En consecuencia, se declaró infundada el recurso de casación interpuesto por el Banco de la Nación, dado que se consideró que cuando el convenio colectivo ha sido celebrado por una organización sindical de representación limitada, que no goza de la representatividad de la mayoría de los trabajadores, no puede extender los efectos del convenio colectivo de este sindicato a los no afiliados, salvo disposición en contrario expresado en el propio convenio colectivo, o cuando limite al trabajador su ejercicio del derecho constitucional a la libertad sindical individual positiva, respecto a la facultad de afiliarse a un sindicato.

En resumen, como se logra apreciar de las cuatro casaciones comentadas, se trata acerca de reclamos de trabajadores no 
Jorge Toyama Miyagusuku y Alfredo Torres

sindicalizados por recibir los beneficios de los convenios colectivos suscritos por sindicatos minoritarios. La excepción es la Casación Laboral No. 10766-2013-Moquegua, que reclama el sindicato para que se le otorgue los pagos que se realizaron de manera voluntaria a los demás sindicatos y a los no afiliados. Sin embargo, dichos pagos no tuvieron como propósito, como ya sabemos, generar desigualdades, sino más bien lo contrario, mantener la igualdad referente a los beneficios económicos tanto para los trabajadores afiliados a los sindicatos como para los no afiliados.

Ahora bien, precisamos que el reciente pronunciamiento del máximo órgano del Poder Judicial permite la extensión de convenios colectivos (Casación Laboral No. 16995-2016LIMA) en la situación de que el convenio colectivo así lo indique, con lo cual no nos entramos ante una prohibición absoluta de la extensión del convenio colectivo, sino más bien a su apertura en casos concretos.

Finalmente, cabe indicar que las resoluciones de la Corte Suprema no versan, en rigor, sobre la pretensión de anulación de una extensión del convenio colectivo a los trabajadores no sindicalizados. En todos los casos, se trata de trabajadores que requieren al Poder Judicial para que se ordene la extensión del convenio colectivo. En rigor, la facultad de la empresa de extender un convenio colectivo no ha sido analizada por la Corte Suprema.

\subsection{SUNAFIL: ¿postura razonable?}

La Superintendencia Nacional de Fiscalización Laboral mediante Resolución de Intendencia No. 283-2015-SUNAFIL/ ILM (última instancia en sede administrativa), resolvió un procedimiento sancionador en contra del BBVA Banco Continental por supuestas vulneraciones a la normativa laboral, específicamente de los artículos 4, 41 y 70 del TUO de la LRCT.

El procedimiento sancionador investigó la supuesta infracción de si la entrega de la bonificación ocasionó la desafiliación al sindicato. De esta manera, la SUNAFIL llegó a la conclusión de que, aun habiéndose emitido el laudo arbitral, según la cual la bonificación extraordinaria solo puede entregarse a los trabajadores afiliados y que ello, estando a que el Laudo Arbitral obedece al acuerdo de ambas partes, ninguna de ellas está legitimada a incumplirlo.

Sin embargo, la SUNAFIL consideró que dicha cláusula arbitral no limita la facultad del empleador de conceder, a título de liberalidad, cantidades idénticas o similares de bonificaciones a sus trabajadores. De esta manera, la Resolución debió determinar no solo la existencia del otorgamiento de un bono extraordinario en beneficio de los trabajadores no sindicalizados, sino, además, si es que dicho otorgamiento afectó la libertad sindical, a efectos de que se configure una infracción a la que se refiere el numeral 25.10 del artículo $25^{(7)}$ del Reglamento de la Ley General de Inspección del Trabajo (En adelante, "RLGIT").

En consecuencia, dado cuenta que no se ha acreditado la afectación a la libertad sindical en atención a lo verificado y probado en el presente procedimiento, no se multó al mencionado Banco.

De esta manera, coincidimos con la presente resolución de la SUNAFIL en tanto que la extensión de los convenios colectivos a los no afiliados inminentemente no generan una vulneración a la libertad sindical de la organización. Más bien, si en todo caso existiese tal vulneración, esta debe ser probada indicando cual es el daño y cuál fue la responsabilidad del empleador.

(7) Artículo 25.10 del RLGIT: "La realización de actos que afecten la libertad sindical del trabajador o de la organización de trabajadores, tales como aquellos que impiden la libre afiliación a una organización sindical, promuevan la desafiliación de la misma, impidan la constitución de sindicatos, obstaculicen a la representación sindical, utilicen contratos de trabajo sujetos a modalidad para afectar la libertad sindical, la negociación colectiva y el ejercicio del derecho de huelga, o supuestos de intermediación laboral fraudulenta, o cualquier otro acto de interferencia en la organización de sindicatos". 


\section{Extensión de los Convenios Colectivos de Trabajo y Sindicatos Minoritarios Extension of the Collective Labour Agreement and Minority Unions}

\section{Propuesta de solución}

A lo largo del presente artículo, se apreció que existe mucho dualismo entorno a la aceptación o no de la extensión de los convenios colectivos suscritos por un sindicato minoritario y ello se evidencia tanto en los pronunciamientos del Tribunal Constitucional, como también en la Corte Suprema y como también en la SUNAFIL.

Para nosotros, es válido que un empleador extienda los efectos de un convenio colectivo a los trabajadores no sindicalizados. No puede prohibirse esta libertad de extensión en desmedro de la libertad sindical negativa. Si se impide la extensión de un convenio colectivo de un sindicato minoritario, el resto de trabajadores no tendría la posibilidad de recibir incrementos o beneficios unilaterales del empleador (porque sería anti sindicales).

En todo caso, proponemos una solución intermedia en la cual la fiscalización ya no se realice ex post, sino todo lo contrario, sea parte de un procedimiento ex ante resuelto por la Autoridad Administrativa de Trabajo, tal como sucede en el caso de la suspensión temporal perfecta de labores por caso fortuito o fuerza mayor o bien como sucede en caso de la terminación colectiva de los contratos de trabajo por causa objetiva, conforme se aprecia en el TUPA del Ministerio de Trabajo y Promoción del Empleo.

Este mecanismo de control de la extensión de convenios colectivos lo posee España y se encuentra regulada por el Real Decreto 718/2005, la misma que, en base a criterios especificados en dicho decreto, aprueba o no las extensiones de convenios colectivos. En otras palabras, es una entidad independiente la que aprueba o no la extensión en base a criterios ya definidos, conforme se aprecia del artículo 9 de la mencionada norma se indica que:

"La resolución administrativa que se dicte decidirá motivadamente, en función de la concurrencia de las circunstancias establecidas en el artículo 92.2 del texto refundido de la Ley del Estatuto de los Trabajadores y en el artículo 1.2 de este real decreto, sobre la procedencia o no de la extensión de las disposiciones del convenio colectivo solicitado al ámbito requerido carente de regulación".

En efecto, en España la lógica de extender los convenios colectivos surge dados los perjuicios derivados para aquellos trabajadores que se les imposibilita suscribir en su ámbito un Convenio Colectivo debido a la ausencia de partes legitimadas para ello(8). Lo cual nos indica, que en ciertos casos si es posible admitir la extensión de los convenios colectivos a los no sindicalizados, con lo cual está deberá ser evaluada caso por caso por la autoridad respectiva.

\section{Conclusiones}

El derecho colectivo del trabajo es un derecho complejo dado que engloba tres derechos fundamentales laborales: derecho a la libertad sindical, derecho a la negociación colectiva y derecho de huelga. Asimismo, estos derechos a su vez cuentan con otros derechos. Es el caso, por ejemplo, del derecho a la libertad sindical que tiene una esfera individual (positiva y negativa) y colectiva. Con referencia al derecho de libertad sindical individual positiva, esta se encuentra referida a la posibilidad que tiene el trabajador de formar su propio sindicato. Mientras que, en el caso de la faz negativa de la libertad sindical individual, esta protege el derecho a la no sindicalización o bien a la desafiliación. Ambas fases de la libertad sindical (positiva y negativa) deben ser respetadas y protegidas sin ninguna valorización de una sobre la otra, sino consideradas ambas como partes de un mismo derecho que coexisten en igualdad de condiciones.

Ahora bien, considerando lo antes dicho, y respecto a la negociación colectiva

(8) Consulta realizada a la página web del Ministerio de Empleo y Seguridad Social dl Gobierno de España: http://www.empleo. gob.es/es/Guia/texto/guia_12/contenidos/guia_12_24_3.htm. 
Jorge Toyama Miyagusuku y Alfredo Torres

(procedimiento) y al convenio colectivo (producto), debemos indicar que ambos conceptos se encuentran garantizados y protegidos por nuestra Constitución y el aparato internacional laboral (OIT y Comité de Libertad Sindical).

En este sentido, nuestro ordenamiento jurídico sostiene que para que el convenio colectivo tenga eficacia personal general, el sindicato debe tener mayoría absoluta de afiliados, es decir, cuando el sindicato cuente con más del $50 \%$ de afiliados en el ámbito de empresa. Si el sindicato es minoritario, el producto negocial solo afectará a los afiliados al sindicato.

Sin embargo, existen casos en los cuales se podrían considerar que se extienda el convenio colectivo del sindicato minoritario; no obstante, que el sindicato no tenga representatividad, dado que no todo tipo de extensión genera inevitablemente un agravio, ofensa o daño al derecho de libertad sindical de la organización sindical, cualquiera sea su ámbito (individual o colectivo). Es en base, a esta última apreciación, que consideramos que es factible que se extienda el convenio colectivo, siempre y cuando no se vulnere el derecho de libertad sindical.

Nosotros consideramos que la extensión del convenio colectivo de un sindicato minoritario es constitucional, se basa en la libertad de empresa y busca no perjudicar a quien ejerce la libertad sindical negativa. Si se impide la extensión del convenio colectivo, los trabajadores no sindicalizados no tendrían incrementos ni aumentos (dado que la entrega de beneficios solo a los trabajadores no sindicalizados sería anti sindical); esto es, el ordenamiento obligaría a los trabajadores para que se afilien al sindicato para que puedan percibir beneficios. Esto último no debería ser la consecuencia: tanto la libertad sindical positiva como la negativa merecen la misma tutela.

Finalmente, considerando que no existe un criterio univoco a nivel jurisprudencial, proponemos la alternativa de que sea el MTPE quien acepte o no la extensión de convenios colectivos a solicitud de las partes legitimadas, tal como sucede con otros procedimientos (por ejemplo, suspensión perfecta de labores, aceptación del cese por terminación colectiva, etcétera).

\section{Referencias bibliográficas}

Ferrojali, Luigi. 2004. Derechos y garantías. La ley del más débil. $4^{\mathrm{a}}$ ed. Madrid: Editorial Trotta.

Ganoza Gerónimo, Mónica Patricia. 2017. La negociación colectiva en los sindicatos minoritarios y la extensión de sus beneficios a los no sindicalizados. Trabajo Académico para optar el grado de segunda especialidad en Derecho del Trabajo y de la Seguridad Social, Pontifica Universidad Católica del Perú.

Neves Mujica, Javier. 2009. Introducción al Derecho del Trabajo. Lima: Fondo Editorial de la Pontificia Universidad Católica del Perú.

\section{Editores.}

2016. Derecho Colectivo de Trabajo. Lima: Palestra

Organización Internacional del Trabajo. 2006. La Libertad Sindical: Recopilación de decisiones y principios del Comité de Libertad Sindical del Consejo de Administración de la OIT. $5^{\mathrm{a}}$ ed.

Tribunal Constitucional. 2005. Exp. No. 008-2005-Al.

Villavicencio, Alfredo. 2010. La libertad Sindical en el Perú: Fundamentos, alcances y regulación. Lima: OIT-PLADES. 